\title{
Optimization of Saffron Essential Oil Nanoparticles Using Chitosan-Arabic Gum Complex Nanocarrier with Ionic Gelation Method
}

\author{
Fitri Astutiningsih $\mathbb{D}^{1,2}$ Sri Anggrahini, ${ }^{1}$ Aprilia Fitriani $\mathbb{D}^{1},{ }^{3}$ and Supriyadi Supriyadi ${ }^{1}{ }^{1}$ \\ ${ }^{1}$ Department of Food Technology and Agricultural Products, Faculty of Agricultural Technology, Universitas Gadjah Mada, \\ Flora Street No. 1, Sleman, Special District of Yogyakarta 55281, Indonesia \\ ${ }^{2}$ Food Technology, Slamet Riyadi University, Sumpah Pemuda Street No. 18, Kadipiro, Surakarta, Central Java 57136, Indonesia \\ ${ }^{3}$ Food Technology, Faculty of Industrial Technology, Universitas Ahmad Dahlan, Jenderal Ahmad Yani Street, Banguntapan, \\ Bantul, Special District of Yogyakarta, Indonesia
}

Correspondence should be addressed to Supriyadi Supriyadi; suprif248@ugm.ac.id

Received 1 June 2021; Revised 18 December 2021; Accepted 27 January 2022; Published 7 March 2022

Academic Editor: Rosana G. Moreira

Copyright (c) 2022 Fitri Astutiningsih et al. This is an open access article distributed under the Creative Commons Attribution License, which permits unrestricted use, distribution, and reproduction in any medium, provided the original work is properly cited.

\begin{abstract}
This study is aimed at optimizing the Saffron essential oil (SEO) nanoparticles using the ionic gelation method. Response surface methodology (RSM) with Box-Behnken design (BBD) was applied to investigate the optimum conditions and the effects of three independent variables: LWCS concentration (0.1-0.3\%), Arabic gum concentration (9.6-9.8\%), and ratio (core: wall material) $(1: 5,1: 7.5,1: 10)$ on the responses of $z$-average, polydispersity index (PDI), and zeta potential. The results showed that the quadratic model developed from the RSM was statistically significant ( $p$ value $<0.05)$. The quadratic model can be used to describe well the relationship between the variables on the response observed. The lack of fit was nonsignificant $(p$ value $>$ $0.05)$ relative to pure error for all response variables, indicating that the model fitted well. The model equation obtained for the process through RSM was adequate. The LWCS concentration and Arabic gum concentration had a significant effect on $z$ -average and PDI. The ratio (oil: Arabic gum/LWCS) has a significant effect on zeta potential. The optimum condition was the LWCS concentration of $0.1 \%$ and Arabic gum concentration of $9.6 \%$, and the ratio (oil: Arabic gum/LWCS) $1: 5$ produced the optimum SEO nanoparticles with a $z$-average value of 16.24 , PDI of 0.495 , and zeta potential of 15.76 . The verification values were close to the predictive value given by the Design Expert ${ }^{\circledR} 12$ program with $p$ value $>0.05$ at the $95 \%$ confidence level. Therefore, the application of the RSM with Box-Behnken was suitable for optimizing the saffron oil nanoparticles with desirable responses.
\end{abstract}

\section{Introduction}

Saffron (Crocus sativus L.) is the most expensive spice in the world [1]. Saffron is a rich source of rare $\mathrm{C}_{20}$ apocarotenoids with a variety of functional properties. These apocarotenoids are crocins, picrocrocin, and safranal [2]. Food industries extensively use saffron essential oil (SEO) as coloring and flavoring for foods [3]. SEO can be incorporated in food products, drinks, and beverages for its antimicrobial, antioxidant, and flavoring properties to improve the quality $[4,5]$. However, SEO still faces low stability, susceptibility to oxida- tion (heat, oxygen, and light), and loss of flavor during processing and storage [6]. The stability of bioactive compounds in SEO can be improved and protected by converting them into saffron essential oil nanoparticles.

Among the various methods developed to prepare saffron essential oil nanoparticles, the ionic gelation technique has attracted considerable attention because this process is nontoxic, organic solvent-free, convenient, and controllable [7]. It is based on the interactions between the positively charged amino group of chitosan and the negatively charged groups of a polyanion [8]. These interactions form a 
polyelectrolyte complex bond on the particle surface, increasing the mechanical strength of the particles $[9,10]$. Hosseini et al. [11] proposed nanoencapsulation of oregano EO by ionic gelation technique using chitosan nanoparticles. The data shows a $z$-average ranging from 10 to $60 \mathrm{~nm}$ and encapsulation efficiency of $77.8 \%$. Then, Jamil et al. [12] prepared cardamom EO nanoparticles with chitosan using the ionic gelation technique. They formed the nanoparticles in a size range of $50-100 \mathrm{~nm}$.

The choice of wall material is critical because it can affect the various attributes of the nanoparticles, including particle size, encapsulation efficiency, stability of bioactive compounds during storage, and food release [13, 14]. Several wall materials have been widely used for nanoparticles such as Arabic gum for saffron bioactive compound [15], low molecular weight chitosan (LWCS) for insulin [16], maltodextrin for saffron petal's anthocyanins [17], pectin, and whey for saffron extract encapsulation [18].

Low molecular weight chitosan (LWCS) is a class of third-generation biopolymers obtained from modifying chitosan through a depolymerization process to produce polymers with lower molecular weight and water-soluble [19]. LWCS can be used as a coating because it is food grade, nontoxic, and biodegradable. Due to the ionization of the amine groups of this biomolecule in acidic $\mathrm{pH}$ values, chitosan becomes water-soluble and positively charged. This feature provides a basis for the reaction of chitosan with other negatively charged macromolecules such as Arabic gum, carboxymethyl cellulose, alginate, and heparin, resulting in the formation of complexed nanoparticles. Various reports have been presented about the reaction of LWCS with different biopolymers/ions to prepare nanoparticles such as LWCS and Arabic gum for saffron extract [20] LWCS and alginate for mangosteen microparticles [21]. Fan et al. [22] prepared monodisperse low molecular weight chitosan nanoparticles with ionic gelation. The optimized nanoparticles exhibited a particle size range of $138 \mathrm{~nm}$ with a polydispersity index (PDI) of 0.026 and a zeta potential of $+35 \mathrm{mV}$. Thus, in this study, we choose to use LWCS with a high degree of deacetylation.

Arabic gum is a nontoxic and polyanion hydrophilic biopolymer. The compact structure of Arabic gum gets easily opened in neutral $\mathrm{pH}$ values due to the dissociation of its carboxyl groups, resulting in a high level of negatively charged groups [23]. This was providing a suitable reaction with chitosan during ionic gelation [24]. Therefore, LWCS when mixed with Arabic gum is very good at forming polyelectrolyte complexation. It is supposed that the electrostatic complex between LWCS and Arabic gum could form strong viscoelastic films around oil droplets and provide them with a physical-chemical barrier against oxidation [25]. Avadi et al. [26] study develops insulin nanoparticles using chitosan and Arabic gum with an ionic gelation method. The developed nanoparticles showed the $z$-average between 172 and $205 \mathrm{~nm}$, PDI 0.26 , and zeta potential $41.2 \mathrm{mV}$.

An optimization process of formulation parameters is required to obtain the optimum condition of saffron essential oil nanoparticles. Since many parameters need to be studied when preparing the optimum nanoparticles, conven- tional experimental designs for optimizing all parameters are costly and time-consuming. Alternatively, numerical methods such as response surface methodology (RSM) can minimize the difficulties of conventional experimentation [27]. RSM is a statistical and mathematical approach that uses a second-degree polynomial model to study the relationship between one or more response variables and several independent variables using univariate or multivariate models [28]. The optimum conditions are obtained by using complex experimental designs including three-level full factorial design, central composite designs (CCD), BoxBehnken design (BBD), or Doehlert matrix (DM). BBD is one of the multivariate optimization techniques based on three-level incomplete factorial designs which were used for the second-order response surface model. According to Ferreira et al. and Klaus et al., BBD is superior to other response surface designs (e.g., three-level full factorial design, CCD, and DM) because it has no axial point, which contributes to the accomplishment of fewer costs of experimentation and reduces the experimental runs in analytical optimization. RSM has been widely used for optimizing the formulation of red palm oil nanoemulsions [29], Dlimonene nanoencapsulation [30], fucoxanthin-rich oil nanoemulsion [31], and coconut shell liquid smoke nanoencapsulation [32].

This study is aimed at determining the optimal conditions of SEO nanoparticles based on the parameters of low molecular weight chitosan (LWCS) concentration, Arabic gum concentration, and the ratio between (core: wall material). Optimization is done by using the response surface methodology based on Box-Behnken design.

\section{Materials}

Saffron essential oil was purchased from RV Essential, New Delhi. Arabic gum was purchased from Jumbo Trading, Thailand. Low molecular weight chitosan (LWCS) is derived from shrimp shells [33]. The chemicals were $\mathrm{CH}_{3} \mathrm{COOH}$ (Merck, Germany), Polysorbate Tween 80 (Sigma-Aldrich, Singapore), Sodium Tripolyphosphate (STPP) (CV. Progo Mulyo, Yogyakarta), Ethanol (Merck, Germany), and Hexane (Merck, Germany).

\section{Methods}

3.1. Preparation of Saffron Essential Oil Nanoparticle. Saffron essential oil (SEO) nanoparticle was made according to previously described procedures by Ahmadi et al. [34], with some modification. In brief, several amounts of LWCS were dissolved in $25 \mathrm{~mL}$ of acetic acid solution $(1 \% v / v)$ under magnetic stirring for $10 \mathrm{~min}$ at $1500 \mathrm{rpm}$ at room temperature. Then, several amounts of Arabic gum were dissolved in $25 \mathrm{~mL}$ of distilled water, respectively, under magnetic stirring for $30 \mathrm{~min}$ at $1500 \mathrm{rpm}$ at room temperature until homogenous. About $1 \mathrm{~mL}$ of polysorbate (Tween ${ }^{\circledR} 80$ ) as an emulsifier for EO was added to the chitosan solution and allowed to stir for $10 \mathrm{~min}$ at room temperature to obtain a homogeneous solution. Then, several amounts of SEO were dropped into the chitosan/Tween 80 solution and 
stirred for $30 \mathrm{~min}$ at $700 \mathrm{rpm}$ at room temperature. Subsequently, Arabic gum was incorporated into the solution dropwise. Agitation continued at the same rate for $30 \mathrm{~min}$ at room temperature. The sodium tripolyphosphate (STPP) solution was separately prepared by dissolving $0.04 \mathrm{~g}$ of TPP in $10 \mathrm{~mL}$ of distilled water. Finally, the TPP solution was slowly added to the previous solution by stirring at $700 \mathrm{rpm}$ for $10 \mathrm{~min}$ at room temperature. After that, the nanoparticle suspension sample was analyzed for $z$-average, polydispersity index (PDI), and zeta potential using the Nano Zetasizer (Malvern Zetasizer Nano Series Ver 6.20, Malvern Instruments Ltd., UK).

3.2. Spray Drying. The SEO nanoparticle dispersion was spray-dried with spray drying (Lab-Plant SD-05, Keison Products, UK) at inlet temperature $140^{\circ} \mathrm{C}$, outlet temperature $100^{\circ} \mathrm{C}$, with flow rate $5.1 \mathrm{~mL} / \mathrm{min}$. The dried powder was collected and stored in dark bottles and air-tight containers at $4^{\circ} \mathrm{C}$ until further analysis.

\section{Optimization of Saffron Essential Oil Nanoparticle Using Response Surface Methodology with Box-Behnken Design}

Response surface methodology with Box-Behnken design was used to investigate the effects of three independent variables: LWCS concentration, Arabic gum concentration, and ratio (core: wall material) on the responses of $z$-average, polydispersity index (PDI), and zeta potential of the SEO nanoparticles. The three independent variables were investigated at three levels $(-1,0,1)$ obtained from the preliminary assay. The coded and uncoded variables were used in Table 1.

The saffron essential oil nanoparticles were fitted using a second-order polynomial equation, and multiple regression of the data was carried out for obtaining an empirical model related to the most significant factors. The general form of the second-order polynomial equation is referred to Equation (1).

$$
Y=\beta_{0}+\sum \beta_{i} x_{i}+\sum \beta_{i i} x_{i}^{2}+\sum \beta_{i j} x_{i} x_{j}
$$

$Y$ is the predicted response, $x_{i}$ and $x_{j}$ are independent factors, $\beta_{0}$ is the model intercept, $\beta_{i}$ is the linear coefficient, $\beta_{i i}$ is the quadratic coefficient, and the $b_{i j}$ is the interaction coefficient. The response variable was then analyzed using ANOVA. The model that gives significance to ANOVA and nonsignificance to the lack of fit is chosen to analyze the variables.

4.1. Verification of RSM Model. Verification of the optimization result model is done by remaking the saffron essential oil nanoparticles according to the optimum conditions obtained from the program. Verification was carried out with two repetitions. The results obtained were compared with the value of the response variable predicted by RSM. The verification was then strengthened through an analyze comparison of mean one-sample $t$-test using SPSS with a
TABLE 1: Actual levels at coded factor levels of independent variables used in the RSM.

\begin{tabular}{lcccc}
\hline Independent variable & Symbol & \multicolumn{3}{c}{ Coded level } \\
& & -1 & 0 & +1 \\
\hline LWCS (\%) & $X_{1}$ & $0.1 \%$ & $0.2 \%$ & $0.3 \%$ \\
Arabic gum (\%) & $X_{2}$ & $9.6 \%$ & $9.7 \%$ & $9.8 \%$ \\
Ratio (oil: AG/LWCS) & $X_{3}$ & $1: 7.5$ & $1: 5$ & $1: 10$ \\
\hline
\end{tabular}

confidence level of $95 \%$. The prediction is declared successful if the verification results are close to or exactly the prediction value $(p$ value $>0.05)$.

4.2. Encapsulation Efficiency. Crocin substances were used as the parameter of efficiency. There were two analyses to determine the encapsulation efficiency, namely, the total trapped crocins and the total crocins on the surface of the encapsulated product.

4.2.1. Total Crocins. A modified method based on Bagheri et al. [35], with some modifications, was used to calculate total crocin SEO nanoparticles. A total of $0.5 \mathrm{~g}$ powder sample was dispersed with $40 \mathrm{~mL}$ distilled water in a flask, and this mixture was homogenized for $30 \mathrm{~min}$ : after which, $40 \mathrm{~mL}$ ethanol-hexane $(4: 3, v / v)$ was added, and the solution was homogenized for $10 \mathrm{~min}$. Then, centrifuged for $10 \mathrm{~min}$ at $4000 \mathrm{rpm}\left(25^{\circ} \mathrm{C}\right)$. The absorption of total crocin was determined at $440 \mathrm{~nm}$ with spectrophotometer UV-Vis (Shimadzu Uv 1601, Kyoto Jepang). Each measurement was carried out in triplicate. Quantification of total crocins was accomplished using crocin standard calibration curves $\left(y=0.52 x-0.031\right.$, with $\left.R^{2}=0.99\right)$.

4.2.2. Surface Crocins. A modified method based on Bagheri et al. [35], with some modification, was used to calculate surface crocin SEO nanoparticles. A total of $0.5 \mathrm{~g}$ powder sample was dispersed with $40 \mathrm{~mL}$ ethanol-hexane $(4: 3, v / v)$ in a flask, and this mixture was homogenized for $30 \mathrm{~min}$. Then, the solution was centrifuged for $10 \mathrm{~min}$ at $4000 \mathrm{rpm}\left(25^{\circ} \mathrm{C}\right)$. The absorption of surface crocin in the upper phase was determined at $440 \mathrm{~nm}$ with spectrophotometer UV-Vis (Shimadzu Uv 1601, Kyoto Jepang). Each measurement was carried out in triplicate. Quantification of surface crocins was accomplished using crocin standard calibration curves $\left(y=0.52 x-0.031\right.$, with $\left.R^{2}=0.99\right)$.

4.2.3. Encapsulation Efficiency. The encapsulation efficiency (\%) of crocins was calculated using the following equation:

$$
\mathrm{EE} \%: \frac{\text { Total crocin-Surface crocin }}{\text { Total crocin }} \times 100 \% \text {. }
$$

4.2.4. Scanning Electron Microscope (SEM). The morphology of nanoparticles was assessed using a Scanning Electron Microscope (SEM) (JED 2300, Japan). For SEM, sample preparation was done by the nanoencapsulated powder sprinkled onto a two-sided adhesive tape and then coated with a thin layer of gold and observed with an accelerated voltage of $320 \mathrm{kV}$ and photographed at 10000x. 
4.3. FTIR. The structure analysis of the samples was examined by Fourier transform infrared (FTIR) (Thermo Nicolet Avatar 370 FT-IR). The samples were crushed and blended with potassium bromide $(\mathrm{KBr})$ and pressed using a manual pellet press. FTIR spectra were scanned and recorded in the wavenumber range of 4000 to $400 \mathrm{~cm}^{-1}$.

\section{Results and Discussion}

5.1. Fitting the Models. Optimization is the process of finding the value of a considered optimal, effective, and efficient variable to achieve the desired results. The desired results were the saffron essential oil nanoparticles with the smallest $z$ -average value $(<100 \mathrm{~nm})$, the polydispersity index $(<1)$, and the maximum zeta potential value $(<-30 \mathrm{mV}$; $>$ $+30 \mathrm{mV}$ ). The optimization of nanoparticles was carried out using the response surface methodology with the BoxBehnken design.

Statistical analysis (ANOVA) results in Table 2 revealed that the experimental data could be represented well with a quadratic polynomial model with a coefficient of determination $R^{2}$ values for $z$-average and PDI dan zeta potential being $0.99,0.9928$, and 0.9686 , respectively (Table 2 ), which means that the contribution of LWCS concentration, Arabic gum concentration, and ratio (oil: Arabic gum/LWCS) is $99 \%$ for the $z$-average value, $99.28 \%$ for the PDI value, and $96.86 \%$ for the zeta potential value. At the same time, the rest is influenced by other variables that are not included in the model as independent variables. If the value of $R^{2}$ is closer to 1 , it is an indication of a better model fitting to actual data [27]. High $R^{2}$ values indicated that the quadratic model was highly efficient for fitting the data under the condition of the experiment [36].

The significant level for the quadratic polynomial model coefficient was determined through ANOVA (see Table 2). Quadratic model is significant with a $p$ value $<0.05$, namely, 0.002 for $z$-average response, $<0.0001$ for PDI, and $<0.0030$ for zeta potential. It can be said that the selected model can be used to describe well the relationship between the variables on the response observed. The lack of fit was nonsignificant $(p$ value $>0.05)$ relative to pure error for all response variables, indicating that the model fitted well.

5.2. Effect of Independent Variables on Response. There were 15 runs with the predicted value of responses shown in Table 3 and ANOVA of all responses shown in Table 4.

5.3. $Z$-Average. The $z$-average measurement is aimed at determining the size distribution of saffron essential oil nanoparticles and at ensuring that the nanoparticles produced are nanometers $\left(10^{-9} \mathrm{~m}\right)$ in size. Based on the data in Table 3, saffron essential oil nanoparticles have size ranges from $16.24 \mathrm{~nm}$ to $23.38 \mathrm{~nm}$. This size is smaller than the result of Tan et al. [37] study that develops curcumin nanoparticles using chitosan and Arabic gum with an ionic gelation method. The developed nanoparticles showed the average diameter in the range of $250-290 \mathrm{~nm}$. This is because of the difference between the molecular weight of saffron essential oil and curcumin.
TABLE 2: Fitting the models.

\begin{tabular}{lcccc}
\hline Response & Models & $R^{2}$ & $\begin{array}{c}\text { Significant }(p \\
\text { value }<0.05)\end{array}$ & $\begin{array}{c}\text { Lack of fit }(p \\
\text { value }>0.05)\end{array}$ \\
\hline$Z$ & Quadratic & 0.9900 & 0.0002 & 0.1942 \\
-average & Quadratic & 0.9928 & $<0.0001$ & 0.1899 \\
$\begin{array}{l}\text { PDI } \\
\begin{array}{l}\text { Zeta } \\
\text { potential }\end{array}\end{array}$ & Quadratic & 0.9686 & $<0.0030$ & 0.1707 \\
\hline
\end{tabular}

Based on ANOVA data (Table 4), the concentration of LWCS and Arabic gum had a significant effect because they had $p$ values of 0.01280 and $0.003(<0.05)$. Meanwhile, the ratio (oil: Arabic gum/LWCS) did not significantly affect the $z$-average value $p$ value of $0.4075(>0.05)$. The interaction between the Arabic gum concentration and the LWCS concentration and the interaction between the Arabic gum and the ratio (oil: Arabic gum/LWCS) also had a significant effect with $p$ values of 0.0426 and $0.0050(<0.05)$, respectively. Meanwhile, the interaction between the LWCS concentration and the ratio (oil: Arabic gum/LWCS) did not significantly affect because the $p$ value was $>0.05$. A larger $F$ value and a smaller $p$ value indicated a highly significant effect on response variables [38].

The equation obtained from the quadratic model for the $z$-average response is as follows:

$$
\begin{aligned}
Y= & 19.45+0.6322 A+1.51 B-0.1087 C-0.4600 A B \\
& -0.0706 A C-0.2260 B C-1.52 A^{2}+1.91 B^{2}-0.0815 C^{2},
\end{aligned}
$$

where $A$ is the LWCS concentration, $B$ is the Arabic gum concentration, and $C$ is the ratio (oil: Arabic gum/LWCS).

Equation (3) shows that the increase in the $z$-average response value is due to the increasing LCWS and Arabic gum concentration indicated by a positive constant value. Therefore, more electrostatic interactions between the chitosan amino group $\left(-\mathrm{NH}^{+}\right)$and the Arabic gum carboxyl group (-COO-) form a polyelectrolyte complex that produces larger nanometer-sized particles [39]. The response of the $z$-average value will also decrease as the ratio (oil: Arabic gum/LWCS) increases. According to Hadidi et al. [40], increasing chitosan/TPP content causes decreasing the sizes of nanoparticles.

5.4. Polydispersity Index (PDI). Polydispersity index (PDI) is a value that shows the ratio between the average molecular mass weight and the average number of molecules where the value range is between 0 and 1 . PDI demonstrates the homogeneity of particle size distribution and is one of the most critical formulation aspects in systems containing fine particles [41]. The values near zero indicate the higher homogeneity, and the values higher than 0.5 show the heterogeneity of particle size distribution [42].

Based on the data in Table 3, the average PDI value obtained is 0.495 to 0.607 . This shows that the saffron essential oil nanoparticles produced have heterogeneity of particle size distribution so that they tend to aggregate one to each other [43]. 
TABLE 3: Experimental design with coded factor levels of independent variables and predicted values of responses.

\begin{tabular}{lcccccc}
\hline Run & LWCS $(\%)$ & Arabic gum $(\%)$ & Ratio (oil: AG/LWCS) & Z-average $(\mathrm{nm})$ & PDI & Zeta potential $(\mathrm{mV})$ \\
\hline 1 & $(0)$ & $(1)$ & $(1)$ & 22.2 & 0.52 & -12 \\
2 & $(-1)$ & $(-1)$ & $(0)$ & 18.33 & 0.607 & -15.2 \\
3 & $(1)$ & $(0)$ & $(-1)$ & 17.14 & 0.588 & -14.8 \\
4 & $(0)$ & $(0)$ & $(0)$ & 18.7 & 0.586 & -15.3 \\
5 & $(0)$ & $(0)$ & $(1)$ & 16.24 & 0.495 & -15.8 \\
6 & $(1)$ & $(0)$ & $(0)$ & 17.04 & 0.508 & -14.5 \\
7 & $(-1)$ & $(1)$ & $(-1)$ & 17.14 & 0.57 & -15.3 \\
8 & $(-1)$ & $(1)$ & $(0)$ & 19.86 & 0.532 & -14.8 \\
9 & $(0)$ & $(-1)$ & $(-1)$ & 23.38 & 0.521 & -15.3 \\
10 & $(1)$ & $(-1)$ & $(0)$ & 19.69 & 0.523 & -12.2 \\
11 & $(0)$ & $(0)$ & $(1)$ & 16.76 & 0.503 & -14.2 \\
12 & $(0)$ & $(-1)$ & $(-1)$ & 17.68 & 0.52 & -14.8 \\
13 & $(0)$ & $(0)$ & $(0)$ & 17.99 & 0.536 \\
14 & $(-1)$ & $(1)$ & & 17.59 & 0.508 & -14 \\
\hline
\end{tabular}

TABLE 4: ANOVA of $Z$-average, PDI, and zeta potential.

\begin{tabular}{|c|c|c|c|c|c|c|}
\hline \multirow{2}{*}{$\begin{array}{l}\text { ANOVA } \\
\text { Source }\end{array}$} & \multicolumn{2}{|c|}{$Z$-average } & \multicolumn{2}{|c|}{ PDI } & \multicolumn{2}{|c|}{ Zeta potential } \\
\hline & $F$ value & $p$ value & $F$ value & $p$ value & $F$ value & $p$ value \\
\hline Model & 55.21 & 0.0002 & 76.84 & $<0.0001$ & 17.11 & 0.0030 \\
\hline$A$, LWCS \% & 14.37 & 0.0128 & 11.88 & 0.0183 & 0.4031 & 0.5534 \\
\hline$B$, gum $\%$ & 82.26 & 0.0003 & 1.96 & 0.2204 & 71.32 & 0.0004 \\
\hline$C$, ratio oil: GA/LWCS & 0.8171 & 0.4075 & 11.80 & 0.0185 & 0.5989 & 0.4740 \\
\hline$A B$ & 7.31 & 0.0426 & 27.60 & 0.0033 & 9.78 & 0.0260 \\
\hline$A C$ & 2.22 & 0.1963 & 6.98 & 0.0459 & 5.28 & 0.0700 \\
\hline$B C$ & 22.79 & 0.0050 & 9.71 & 0.0264 & 26.73 & 0.0036 \\
\hline$A^{2}$ & 73.31 & 0.0004 & 197.77 & $<0.0001$ & 26.86 & 0.0035 \\
\hline$B^{2}$ & 116.49 & 0.0001 & 104.49 & 0.0002 & 26.86 & 0.0035 \\
\hline$C^{2}$ & 9.20 & 0.0290 & 3.20 & 0.1338 & 2.12 & 0.2051 \\
\hline Lack of fit & 4.31 & 0.1942 & 4.42 & 0.1899 & 5.02 & 0.1707 \\
\hline
\end{tabular}

The ANOVA data shows (Table 4) that LWCS concentration and ratio (oil: Arabic gum/LWCS) had a significant effect with $p$ values of 0.0183 and $0.0185(<0.05)$. Meanwhile, the Arabic gum concentration did not significantly affect the PDl value with a $p$ value of $0.2204(>0.05)$. The interactions occurring between the three independent variables (Arabic gum concentration, LWCS concentration, and ratio (oil: Arabic gum/LWCS)) also have a significant effect with $p$ values of $0.0033,0.0459$, and $0.0264(<0.05)$, respectively. A larger $F$ value and a smaller $p$ value indicated a highly significant effect on response variables [44].

The equation obtained from the model for the PDI response is presented as follows:

$$
\begin{aligned}
Y= & +0.5515+0.0085 A-0.0035 B-0.0061 C \\
& -0.0132 A B-0.0019 A C+0.0022 B C \\
& +0.0369 A^{2}-0.0268 B^{2}-0.0007 C^{2}
\end{aligned}
$$

where $A$ is the LWCS concentration, $B$ is the Arabic gum concentration, and $C$ is the ratio (oil: Arabic gum/LWCS).

Equation (4) shows that the $\mathrm{PDl}$ response value will increase directly proportional to the addition of the LWCS concentration and indicated by a positive constant value. The response of the PDl value will also decrease as the Arabic gum and the ratio (oil: Arabic gum/LWCS) increase. In contrast with Mohammadpour Dounighi et al. [45], PDI decreased as chitosan concentration was raised in reaction with a constant amount of TPP. As mentioned earlier, the reason behind this contradiction could be the difference between TPP and Arabic gum, the target material, and the ratio between chitosan and polyanions.

5.4.1. Zeta Potential. Zeta potential is an important parameter to characterize the surface properties of nanoparticles and is related to electrostatic interactions between particles in colloid systems. The zeta potential value is also used to determine physical stability [46]. A good zeta potential value 
is within the range of $<-30 \mathrm{mV}$ or $>30 \mathrm{mV}$. The higher the zeta potential value, the bigger the repulsive force between the particles due to charge. This then causes the particles to move randomly, and the dispersion system is stable.

Based on Table 3, the zeta potential value between $-12 \mathrm{mV}$ and $-15.76 \mathrm{mV}$ is still low. Thus, it has not reached the desired value $(<-30 \mathrm{mV}$ or $>30 \mathrm{mV})$. The product is still less stable and tends to aggregate. It is presumably due to the weak repulsion between the particles [25]. Dispersion stability occurs when the electrostatic repelling forces between particles are more dominant than their attractive forces. Therefore, it can prevent agglomeration under certain conditions. According to Feyzioglu and Tornuk [47], chitosan nanoparticles loaded with different summer savory essential oil levels had negative zeta potential values varying from -7.54 to $-21.12 \mathrm{mV}$. The sign (-) in the zeta potential value means that the saffron essential oil nanoparticle dispersion system negatively charges. This negative charge indicates that all $\left(-\mathrm{NH}^{+}\right)$LWCS groups have been neutralized by the negative charge from Arabic gum and the STPP cross-linker used. In addition, a negative value on the zeta potential indicates that the nanoparticles are present in the matrix [48].

The Arabic gum concentration significantly affects changes in the zeta potential value with a $p$ value of 0.0004 $(<0.05)$ based on ANOVA data (Table 4). Meanwhile, the LWCS concentration and the ratio (oil: Arabic gum/LWCS) did not have a significant effect with a $p$ value of $>0.05$. The interaction between the Arabic gum concentration and the LWCS concentration and the interaction between the Arabic gum concentration and the ratio (oil: Arabic gum/LWCS) also had a significant effect with $p$ values of 0.0260 and 0.0036 $(<0.05)$, respectively. Meanwhile, the interaction between the LWCS concentration and the ratio (oil: Arabic gum/LWCS) did not significantly affect with a $p$ value of $>0.05$.

The equation obtained from the model for the zeta potential response is presented as follows:

$$
\begin{aligned}
Y= & 14.25+0.0995 A-1.32 B-0.0875 C+0.5000 A B \\
& -0.1022 A C+0.2300 B C+0.8625 A^{2} \\
& -0.8625 B^{2}+0.0368 C^{2},
\end{aligned}
$$

where $A$ is the LWCS concentration, $B$ is the Arabic gum concentration, and $C$ is the ratio (oil: Arabic gum/LWCS).

Equation (4) shows that the zeta potential response value will increase directly proportional to the addition of the LWCS concentration and the Arabic gum concentration and indicated by a positive constant value. The zeta potential response value will also decrease as the Arabic gum concentration and the ratio (oil: Arabic gum/LWCS) increase.

The experimental data collected from the responses of the independent variables were analyzed. The results showed that the quadratic polynomial equation could illustrate the response surface plots and forecast the $z$-average, PDI, and zeta potential of the SEO nanoparticle. Figures 1-3 show the response surface and contour plots of the quadratic polynomial models that present the effect of independent variables on the $z$-average, PDI, and zeta potential of the SEO nanoparticles.
The concentration of LWCS and Arabic gum is a very important parameter that actively affects the $z$-average. The increase in the $z$-average response value is due to the increasing LCWS and Arabic gum concentration. Therefore, more electrostatic interactions between the chitosan amino group $\left(-\mathrm{NH}^{+}\right)$and the Arabic gum carboxyl group (-COO-) form a polyelectrolyte complex that produces larger nanometer-sized particles. Figure 1 shows that the minimum $z$-average value $(16.24 \mathrm{~nm})$ was achieved at LWCS concentration of $0.1 \%$ and Arabic gum concentration at 9.6\%. The ratio (oil: Arabic gum/LWCS) had a significant effect on PDI response. The response of the PDl value will increase as the ratio (oil: Arabic gum/LWCS) increases. Figure 2 shows that the minimum PDI value $(0.495 \mathrm{~nm})$ was achieved at the ratio (oil: Arabic gum/LWCS) of $1: 5$. The zeta potential response value will increase directly proportional to the addition of the Arabic gum concentration. Figure 3 shows that the maximum zeta potential value $(-15.8)$ was achieved at the Arabic gum concentration of $9.6 \%$.

5.5. Optimization and Verification Formula of SEO Nanoparticles. The Design Expert $12{ }^{\circledR}$ program provides 54 formula composition solutions based on determining the importance of each response. The chosen formula is the highest desirability value. The desirability value close to 1 indicates the closeness between the actual value and the predicted value. The optimum formula suggested by the program is the LWCS concentration of $0.1 \%$ and Arabic gum concentration of $9.6 \%$, and the ratio (oil: Arabic gum/ LWCS) was 1:5 with the desirability value of all factors was 1 (see Figure 4).

The optimum formula obtained from RSM was further confirmed by experimenting with the optimum condition. The optimum formula is predicted to produce saffron essential oil nanoparticles with a $z$-average value of $16.2177 \mathrm{mV}$, PDI of 0.4948 , and a zeta potential value of -15.8 (see Figure 4).

The verified result of the optimum formula obtained $z$ -average values of 16.24 , PDI of 0.495 , and zeta potential of 15.76 (Table 5). Compared with the predicted value, the verification result value is in the range of $95 \%$ PI low and 95\% PI high (Table 5). This result means that the chosen formula recommended by the Design Expert program is adequately good. Verification was then strengthened by the one sample $t$-test using SPSS. The results showed that the values were not significantly different $(p$ value $>0.05)$. The experimental data is closer to the predicted value. It can be concluded that the RSM models could be used to study the quadratic effects of LWCS concentration, Arabic gum concentration, and ratio (oil: Arabic gum/LWCS) on the $z$-average, PDI, and zeta potential. Therefore, the application of the RSM with Box-Behnken was suitable for optimizing the saffron oil nanoparticles with desirable responses.

5.6. Encapsulation Efficiency. The total crocins, surface crocins, and encapsulation efficiency for SEO nanoparticles are shown in Table 6 . The total crocin value indicated the amount of all crocins in the inner and surface of SEO 


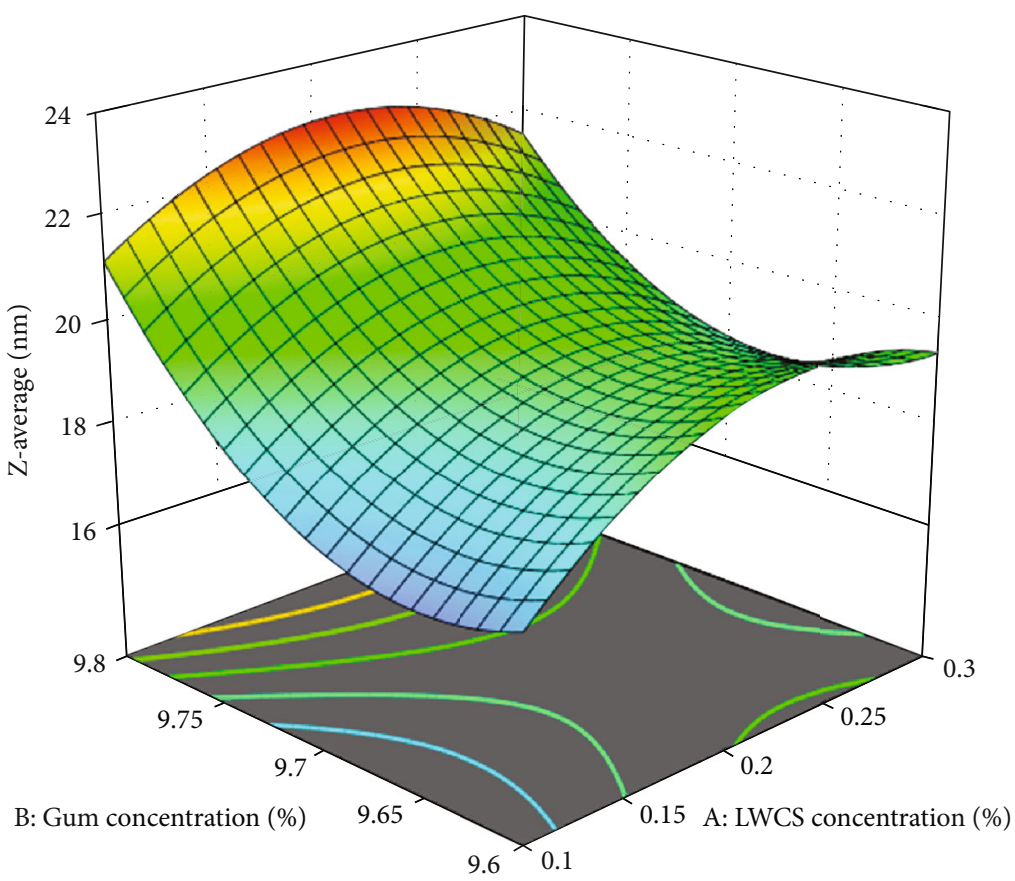

(a)

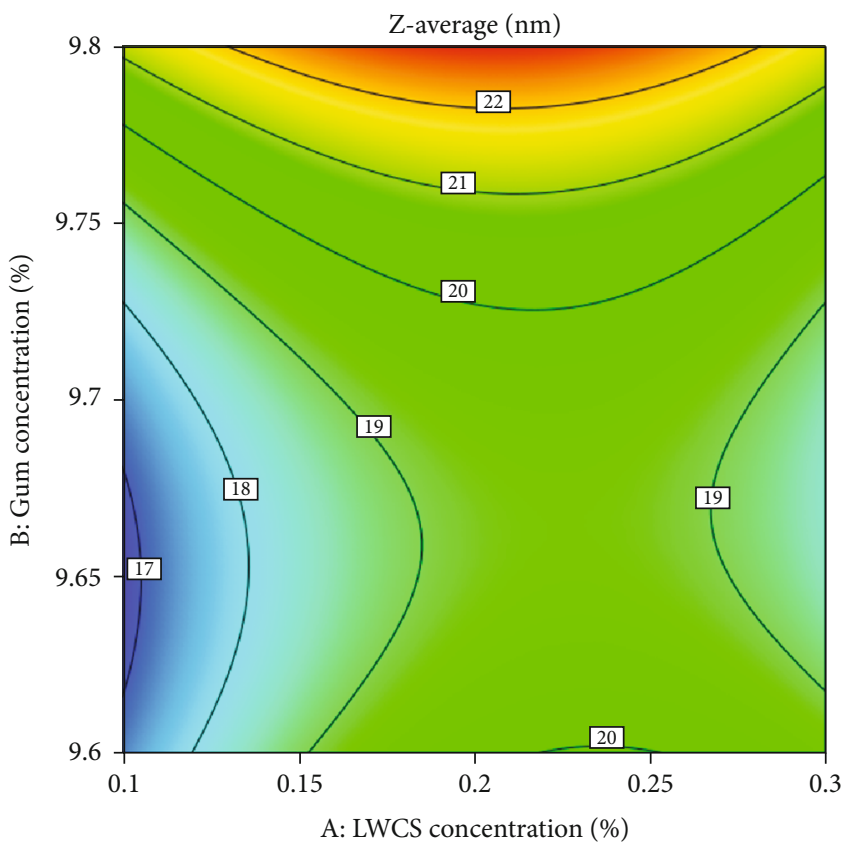

(b)

Figure 1: Surface plot (a) and contour plot (b) for Z-average response.

nanoparticles. The surface crocin value indicates the number of crocins on the surface of the nanoparticle wall. Surface crocins are undesirable because crocins are very easily damaged if exposed to certain oxidants such as air, light, and water $[49,50]$.

Based on the data in Table 6, the saffron essential oil nanoparticles have an encapsulation efficiency value of $86.4 \%$. The value of the encapsulation efficiency in this study is considered high. Atefi et al. [51] showed similar results, where the encapsulation efficiency of saffron essen- tial oil with Arabic gum and B-cyclodextrin ranged 72.49$90.51 \%$. Rajabi et al. [15] showed that a mixture of a saffron extract with maltodextrin, Arabic gum, and gelatincoating had a slightly higher encapsulation efficiency (41.95-91.01\%).

Combining two coatings with different charges causes the two polymers to interact ionically to form a polyelectrolyte complex bond [52]. The effect of the polyelectrolyte complex bond between chitosan and Arabic gum will further strengthen the nanoparticle walls to reduce the release 


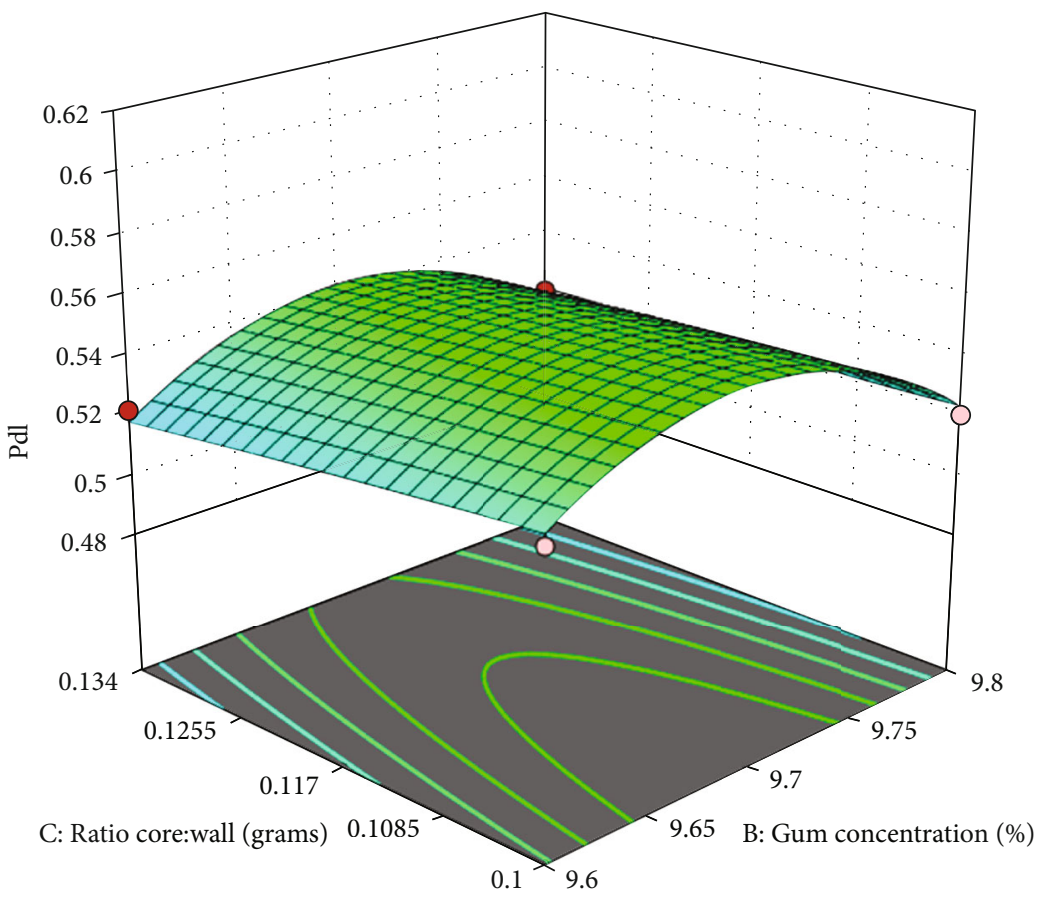

(a)

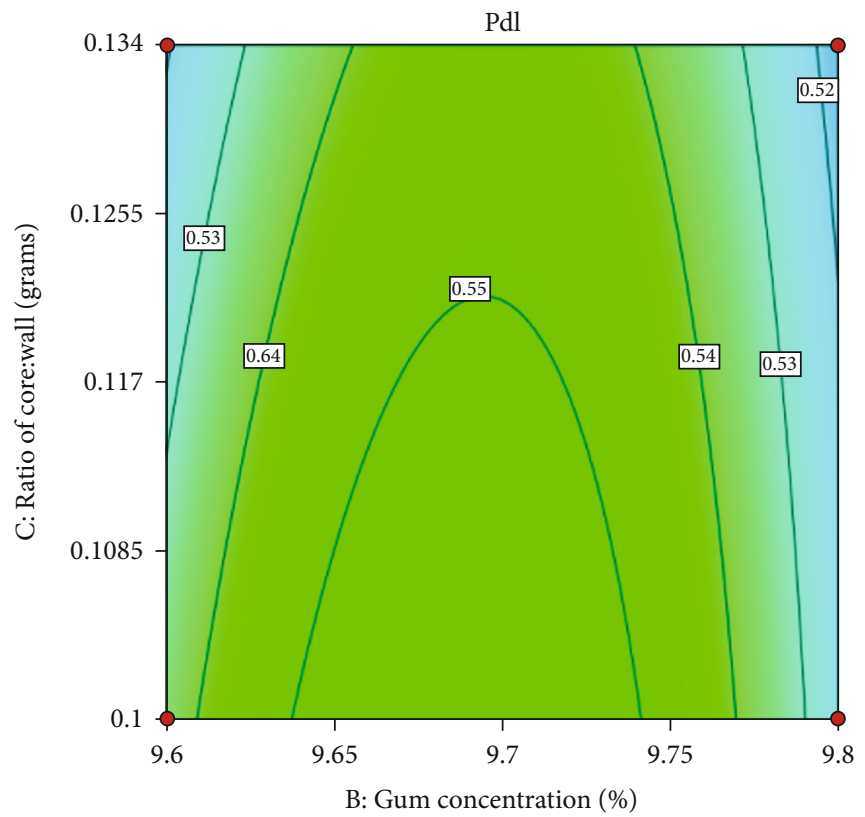

(b)

Figure 2: Surface plot (a) and contour plot (b) for PDI response.

of SEO to the surface. Another factor that strengthens the nanoparticle wall is STPP, which encourages the cross-link reaction between the LWCS from $\mathrm{NH}_{3}^{+}$and the $\mathrm{P}_{3} \mathrm{O}_{5}{ }^{-10}$ functional group from STPP [53]. According to Jafari et al. [54], the encapsulation efficiency is influenced by the drying conditions, emulsion, bioactive compound characteristics, and wall material properties. The drying temperature is directly proportional to the evaporation rate and inversely proportional to the final water content of the dried microparticles. At high drying temperatures, there is a higher evaporation rate of water on the droplet surface, which leads to the rapid formation of a semipermeable membrane, resulting in the protection of the release of the bioactive compounds during the drying process and, consequently, in higher bioactive retention [55]. Wall material concentration is also a factor that affects the retention of the bioactive compounds due to their viscosity properties in the feed solution. The increase of solid content in the feed solution can increase bioactive retention [56-58]. 


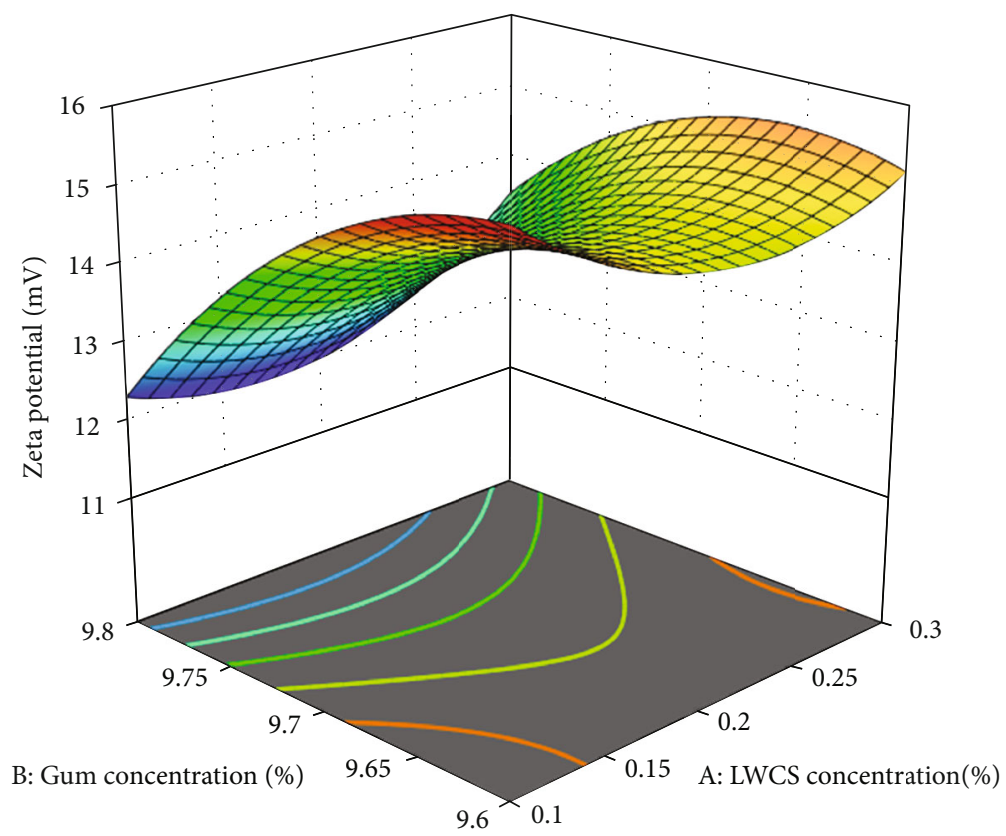

(a)

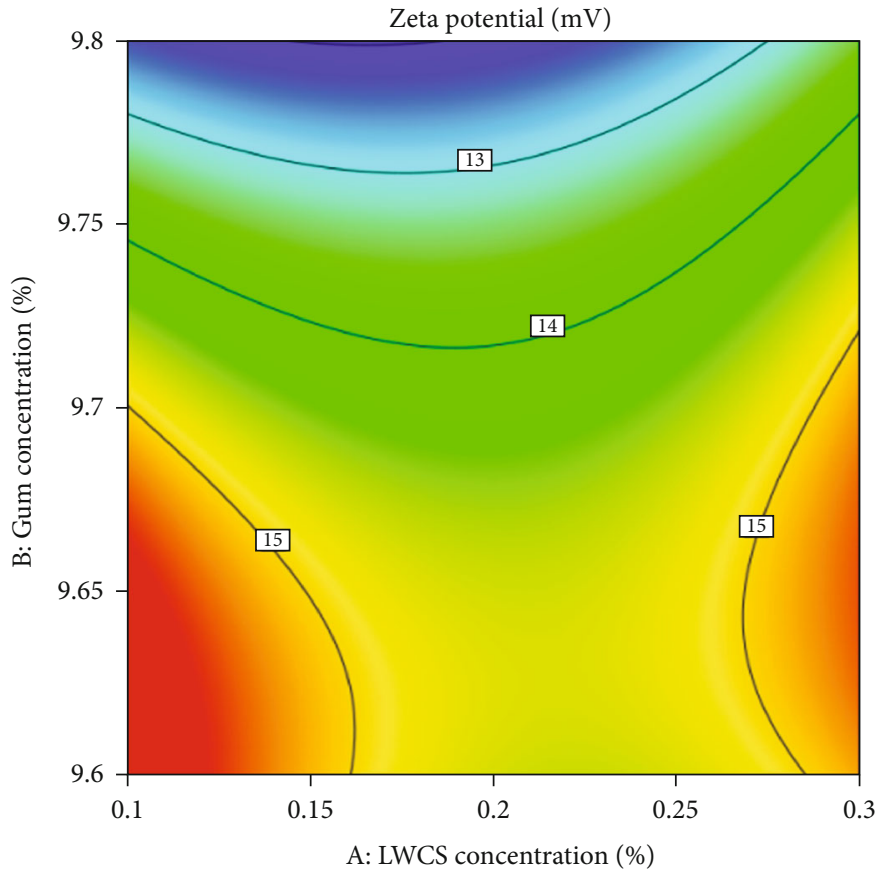

(b)

Figure 3: Surface plot (a) and contour plot (b) for zeta potential response.

5.7. Scanning Electron Microscope (SEM). Observation of the morphological profile of the nanoparticles was carried out using Scanning Electron Microscope (SEM). The observations in Figure 5 show that the nanoparticles are spherical, but some parts are shrinking/deflating. Most of the particles did not present a significant incidence of cracks or fissures in the outer surface, indicating a resistant external physical structure.

A similar morphology is also shown by Harris et al. [59], where the microcapsules produced are round and wavy due to the rapid evaporation of solvents during the spray drying process. According to Mohammed et al. [57], higher drying inlet $\left(>140^{\circ} \mathrm{C}\right)$ temperatures tend to produce particles with a smoother surface. They found nanoparticles morphologically more defined and smoother, without evident cracks or particle agglomerations in the spray drying process both at 160 and $180^{\circ} \mathrm{C}$. This fact may be attributed to rapid water evaporation and higher pressure inside the particles during microencapsulation at higher temperatures preventing shrinking. On the other hand, water diffusion is slower at 

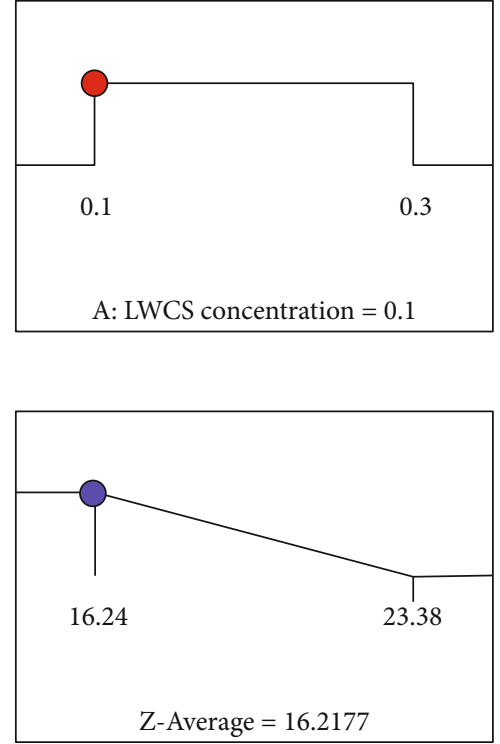

Desirability $=1.000$

Solution 1 out of 54
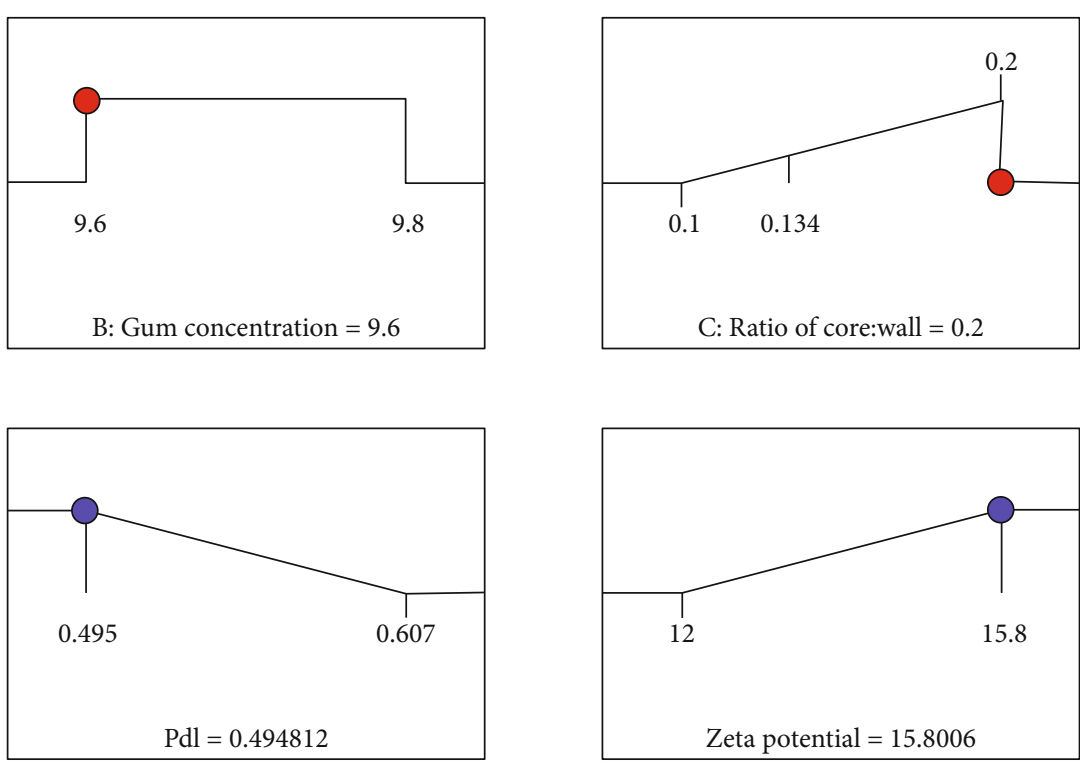

FIgURE 4: The optimum formulation from Design Expert $12^{\circledR}$ program.

TABle 5: Predicted and verification value of $Z$-average, PDI, and zeta potential.

\begin{tabular}{lccccc}
\hline Response & Predicted & Verification & $\begin{array}{c}95 \% \text { PI } \\
\text { low }\end{array}$ & $\begin{array}{c}95 \% \text { PI } \\
\text { high }\end{array}$ & $\begin{array}{c}p \\
\text { value }\end{array}$ \\
\hline$Z$-average & 16.2177 & 16.24 & 15.215 & 17.2203 & 0.972 \\
PDI & 0.494812 & 0.495 & 0.479949 & 0.509676 & 0.987 \\
$\begin{array}{l}\text { Zeta } \\
\text { potential }\end{array}$ & 15.8006 & -15.76 & 14.8582 & 16.7429 & 0.893 \\
\hline
\end{tabular}

TABLE 6: Encapsulation efficiency of saffron essential oil nanoparticles.

\begin{tabular}{lccc}
\hline Ulangan & $\begin{array}{c}\text { Total } \\
\text { crocin }\end{array}$ & $\begin{array}{c}\text { Surface } \\
\text { crocin }\end{array}$ & $\begin{array}{c}\text { Encapsulation efficiency } \\
(\%)\end{array}$ \\
\hline 1 & 1.4076 & 0.1923 & $86.33 \%$ \\
2 & 1.4019 & 0.1884 & $86.56 \%$ \\
3 & 1.4057 & 0.1923 & $86.31 \%$ \\
$\bar{X} \pm \mathrm{SD}$ & 1.4030 & 0.191 & $86.4 \%$ \\
\hline
\end{tabular}

lower temperatures, allowing more time for the particles to deform, wrinkle, and collapse.

Observation of the morphological profile using SEM is only able to see the shape of the surface of the nanocapsules, but the inside of the nanocapsules is not visible, so it is not possible to know the type of encapsulation, either the reservoir form (single-core) or matrix type (matrix core). To better know the type of encapsulation, it is necessary to observe the morphological profile using an infrared scanning electron.

5.8. FTIR. FTIR was used to confirm the linkage between $\left(\mathrm{NH}_{3}{ }^{+}\right)$and (COO-) of LWCS and Arabic gum, respectively, in the SEO nanoparticles (Figure 6). In the LWCS spectra, the broadband overlapping at $3400.90 \mathrm{~cm}^{-1}$ was concerned with the $\mathrm{O}-\mathrm{H}$ groups. The strong band at 1562.48 was associated with the amide III groups $\left(-\mathrm{NH}^{+}\right)$. These peaks are typical peaks indicating the presence of an amine group on the LWCS. In addition, Arabic gum also shows a stretching vibration absorption $\mathrm{C}=\mathrm{O}$ in wave number $1638.2 \mathrm{~cm}^{-1}$.

In the spectra of the SEO nanoparticles, the peaks for $\mathrm{N}$ $\mathrm{H}$ bending vibration of amine $1412.37 \mathrm{~cm}^{-1}$ shifted to $1451.8 \mathrm{~cm}^{-1}$, and $\mathrm{O}-\mathrm{H}$ stretching vibration peaks in wave number $3400.90 \mathrm{~cm}^{-1}$ shifted to $3410.15 \mathrm{~cm}^{-1}$ (Figure 6). These results indicate the interaction between amino groups of LWCS and (COO-) of Arabic gum. We can conclude that the appearance of these peaks is an indication of nanoparticle formation and that the inter- and intramolecular actions are enhanced in chitosan nanoparticles.

The formulation of saffron essential oil nanoparticles is produced through an ionic gelation reaction, which begins with the encapsulation interaction between LWCS and saffron essential oil. After encapsulation of saffron essential oil in the LWCS matrix, a nanoparticle will be formed. Stabilization occurs with the addition of Arabic gum. The (COO-) Arabic gum group will bind with the $\left(\mathrm{NH}^{+}\right)$group of LWCS to form a polyelectrolyte complex bond [60]. As a result, there will be a change in the absorption peak in the IR spectra of the amino group, carboxyl group, and amide group. The strong electrostatic interaction between chitosan and a polyanion causes the shift or loss of distinct groups is caused by [61]. Mukhopadhyay et al. [62] reported a shift in the absorption peak of insulin nanoparticles encapsulated by the chitosan-alginate matrix as polyanions. A shift in the $\mathrm{O}$ $\mathrm{H}$ and $\mathrm{N}-\mathrm{H}$ chitosan stretching vibration peaks in wave numbers $3427 \mathrm{~cm}^{-1}$ to $3469 \mathrm{~cm}^{-1}$ in the insulin nanoparticle spectra. 


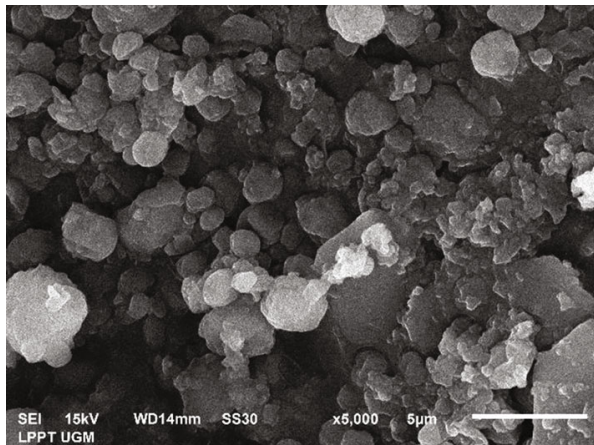

(a)

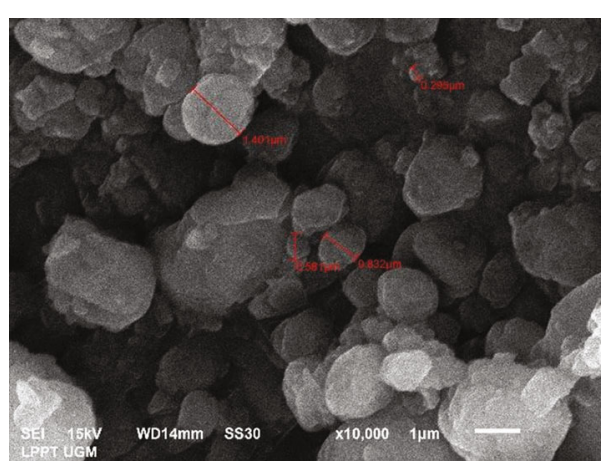

(b)

FIGURE 5: SEM image for saffron essential oil nanoparticles: (a) 5000x; (b) 10.000x.

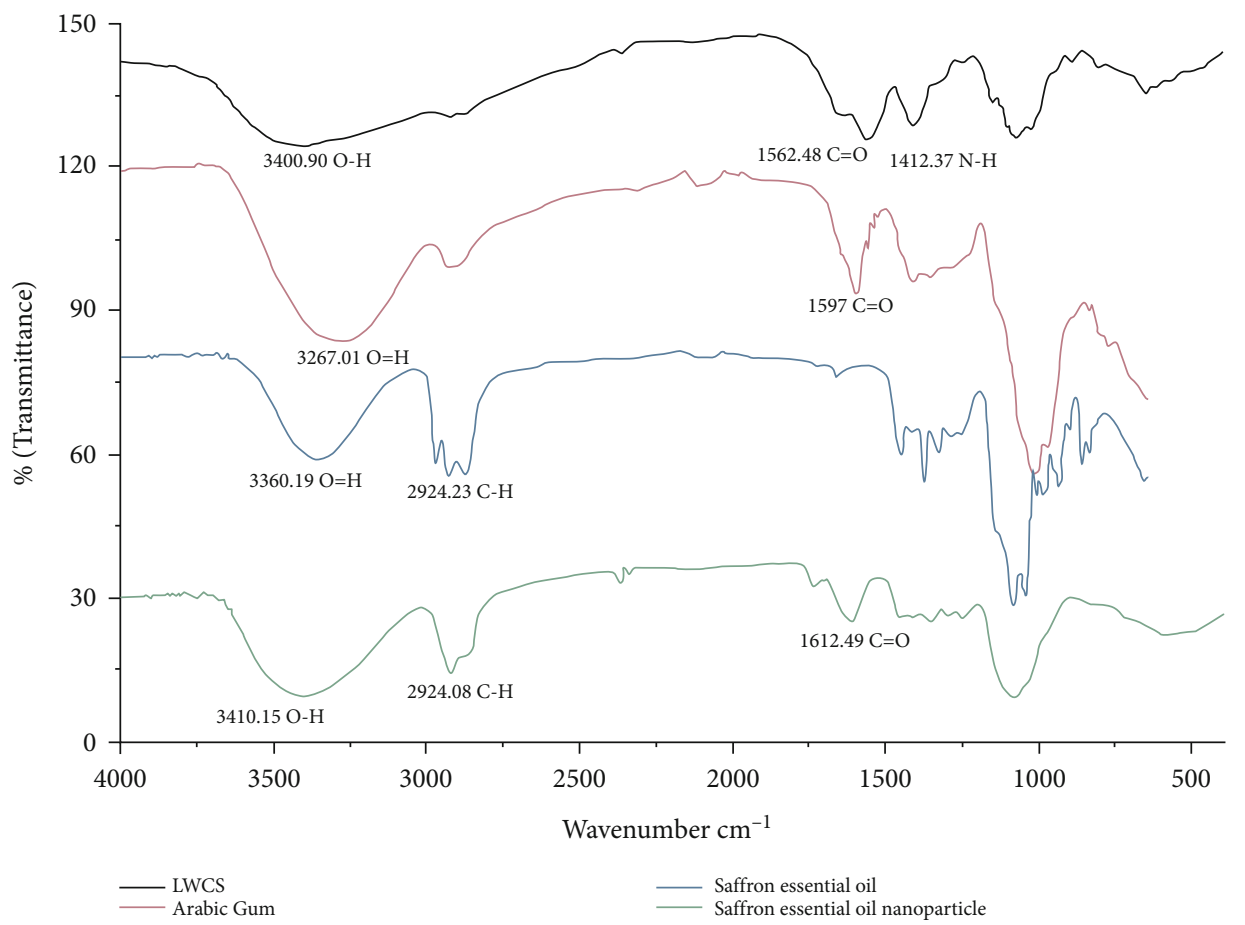

FIGURE 6: FTIR of saffron essential oil nanoparticles.

\section{Conclusions}

Saffron essential oil nanoparticles were successfully prepared via the ionic gelation method through RSM with BoxBehnken design. A quadratic polynomial model was statistically significant ( $p$ value $<0.05$ ). The quadratic model can be used to describe well the relationship between the variables on the response observed. The lack of fit was nonsignificant ( $p$ value $>0.05$ ) relative to pure error for all response variables, indicating that the model fitted well. The model equation obtained for the process through RSM was adequate. The LWCS concentration and Arabic gum concentration had a significant effect on $z$-average and PDI. The ratio (oil: Arabic gum/LWCS) has a significant effect on zeta potential. The optimum formula was observed when LWCS concentration of $0.1 \%$, Arabic gum concentration of $9.6 \%$, and a ratio (oil: Arabic gum/LWCS) of 1: 5. The optimum formulas may produce saffron essential oil nanoparticles with a $z$-average value of 16.2177 , a PDI value of 0.4948 , and a zeta potential value of -15.8 . The verification values were close to the predictive value given by the Design Expert $^{\circledR} 12$ program with ( $p$ value $>0.05$ ) at the $95 \%$ confidence level. Therefore, the application of the RSM with BBD was suitable for optimizing the saffron oil nanoparticles with desirable responses.

\section{Data Availability}

The data used to support the findings of this study are included in the article.

\section{Conflicts of Interest}

The authors declare no conflict of interest. 


\section{Acknowledgments}

The authors would like to thank all of the parties who helped researchers during the research period until writing the manuscript.

\section{References}

[1] J. P. Melnyk, S. Wang, and M. F. Marcone, "Chemical and biological properties of the world's most expensive spice: saffron," Food Research International, vol. 43, no. 8, pp. 1981-1989, 2010.

[2] A. Kyriakoudi, S. A. Ordoudi, M. Roldán-Medina, and M. Z. Tsimidou, "Saffron, a functional spice," Austin Journal of Nutrition and Food Sciences, vol. 3, no. 3, 2015.

[3] K. Zeka, K. C. Ruparelia, M. A. Continenza, D. Stagos, F. Vegliò, and R. R. J. Arroo, "Petals of Crocus sativus L. as a potential source of the antioxidants crocin and kaempferol," Fitoterapia, vol. 107, pp. 128-134, 2015.

[4] N. Moratalla-López, M. J. Bagur, C. Lorenzo, M. E. MartínezNavarro, M. Rosario Salinas, and G. L. Alonso, "Bioactivity and bioavailability of the major metabolites of Crocus sativus L. flower," Molecules, vol. 24, no. 15, p. 2827, 2019.

[5] M. R. Khazdair, M. Hossein Boskabady, M. Hosseini, R. Rezaee, and A. M. Tsatsakis, "The effects of Crocus sativus (saffron) and its constituents on nervous system: a review," Avicenna Journal of Phytomedicine, vol. 5, no. 5, pp. 376391, 2015.

[6] F. Donsì, M. Annunziata, M. Sessa, and G. Ferrari, "Nanoencapsulation of essential oils to enhance their antimicrobial activity in foods," LWT-Food Science and Technology, vol. 44, no. 9, pp. 1908-1914, 2011.

[7] S. A. Agnihotri, N. N. Mallikarjuna, and T. M. Aminabhavi, "Recent advances on chitosan-based micro- and nanoparticles in drug delivery," Journal of Controlled Release, vol. 100, no. 1, pp. 5-28, 2004.

[8] X. Z. Shu and K. J. Zhu, "The influence of multivalent phosphate structure on the properties of ionically cross-linked chitosan films for controlled drug release," European Journal of Pharmaceutics and Biopharmaceutics, vol. 54, no. 2, pp. 235243, 2002.

[9] P. Ahlin Grabnar and J. Kristl, “The manufacturing techniques of drug-loaded polymeric nanoparticles from preformed polymers," Journal of Microencapsulation, vol. 28, no. 4, pp. 323335, 2011.

[10] K. Nagpal, S. K. Singh, and D. N. Mishra, "Chitosan nanoparticles: a promising system in novel drug delivery," Chemical and Pharmaceutical Bulletin, vol. 58, no. 11, pp. 1423-1430, 2010.

[11] S. F. Hosseini, M. Zandi, M. Rezaei, and F. Farahmandghavi, "Two-step method for encapsulation of oregano essential oil in chitosan nanoparticles: preparation, characterization and in vitro release study," Carbohydrate Polymers, vol. 95, no. 1, pp. 50-56, 2013.

[12] B. Jamil, R. Abbasi, S. Abbasi et al., "Encapsulation of cardamom essential oil in chitosan nano-composites: in-vitro efficacy on antibiotic-resistant bacterial pathogens and cytotoxicity studies," Frontiers in Microbiology, vol. 7, pp. 110, 2016.

[13] N. V. N. Jyothi, P. M. Prasanna, S. N. Sakarkar, K. S. Prabha, P. S. Ramaiah, and G. Y. Srawan, "Microencapsulation tech- niques, factors influencing encapsulation efficiency," Journal of Microencapsulation, vol. 27, no. 3, pp. 187-197, 2010.

[14] S. Saloko, P. Darmadji, B. Setiaji, and Y. Pranoto, "Antioxidative and antimicrobial activities of liquid smoke nanocapsules using chitosan and maltodextrin and its application on tuna fish preservation," Food Bioscience, vol. 7, pp. 71-79, 2014

[15] H. Rajabi, M. Ghorbani, S. M. Jafari, A. Sadeghi Mahoonak, and G. Rajabzadeh, "Retention of saffron bioactive components by spray drying encapsulation using maltodextrin, gum Arabic and gelatin as wall materials," Food Hydrocolloids, vol. 51, pp. 327-337, 2015.

[16] M. Kouchak, M. Avadi, M. Abbaspour, A. Jahangiri, and S. K. Boldaji, "Effect of different molecular weights of chitosan on preparation and characterization of insulin loaded nanoparticles by ion gelation method," International Journal of Drug Development and Research, vol. 4, no. 2, pp. 272-277, 2012.

[17] K. Mahdavee Khazaei, S. M. Jafari, M. Ghorbani, and A. Hemmati Kakhki, "Application of maltodextrin and gum Arabic in microencapsulation of saffron petal's anthocyanins and evaluating their storage stability and color," Carbohydrate Polymers, vol. 105, no. 1, pp. 57-62, 2014.

[18] A. Faridi Esfanjani, S. M. Jafari, and E. Assadpour, "Preparation of a multiple emulsion based on pectin-whey protein complex for encapsulation of saffron extract nanodroplets," Food Chemistry, vol. 221, pp. 1962-1969, 2017.

[19] V. K. Mourya and N. N. Inamdar, "Trimethyl chitosan and its applications in drug delivery," Journal of Materials Science: Materials in Medicine, vol. 20, no. 5, pp. 1057-1079, 2009.

[20] H. Rajabi, S. M. Jafari, G. Rajabzadeh, M. Sarfarazi, and S. Sedaghati, "Chitosan-gum Arabic complex nanocarriers for encapsulation of saffron bioactive components," Colloids and Surfaces A: Physicochemical and Engineering Aspects, vol. 578, article 123644, 2019.

[21] E. Krisanti, S. D. Aryani, and K. Mulia, "Effect of chitosan molecular weight and composition on mucoadhesive properties of mangostin-loaded chitosan-alginate microparticles," AIP Conference Proceedings, vol. 1817, 2017.

[22] W. Fan, W. Yan, Z. Xu, and H. Ni, "Formation mechanism of monodisperse, low molecular weight chitosan nanoparticles by ionic gelation technique," Colloids and Surfaces B: Biointerfaces, vol. 90, no. 1, pp. 21-27, 2012.

[23] A. Hosseini, S. M. Jafari, H. Mirzaei, A. Asghari, and S. Akhavan, "Application of image processing to assess emulsion stability and emulsification properties of Arabic gum," Carbohydrate Polymers, vol. 126, pp. 1-8, 2015.

[24] E. Dickinson, "Hydrocolloids as emulsifiers and emulsion stabilizers," Food Hydrocolloids, vol. 23, no. 6, pp. 1473-1482, 2009.

[25] T. Moschakis, B. S. Murray, and C. G. Biliaderis, "Modifications in stability and structure of whey protein-coated $\mathrm{o} / \mathrm{w}$ emulsions by interacting chitosan and gum Arabic mixed dispersions," Food Hydrocolloids, vol. 24, no. 1, pp. 8-17, 2010.

[26] M. R. Avadi, A. M. M. Sadeghi, N. Mohammadpour et al., "Preparation and characterization of insulin nanoparticles using chitosan and Arabic gum with ionic gelation method," Nanomedicine: Nanotechnology, Biology, and Medicine, vol. 6, no. 1, pp. 58-63, 2010.

[27] R. H. Myers, C. M. Anderson, and D. C. Montgomery, Response Surface Methodology: Process and Product Optimization Using Designed Experiments, John Willey and Son Inc., New Jersey, 4th edition, 2016. 
[28] K. Vivek, K. V. Subbarao, and B. Srivastava, "Optimization of postharvest ultrasonic treatment of kiwifruit using RSM," Ultrasonics Sonochemistry, vol. 32, pp. 328-335, 2016.

[29] W. T. Chong, C. P. Tan, Y. K. Cheah et al., "Optimization of process parameters in preparation of tocotrienol-rich red palm oil-based nanoemulsion stabilized by Tween 80 -Span 80 using response surface methodology," PLoS One, vol. 13, no. 8, article e0202771, 2018.

[30] P. H. Li and B. H. Chiang, "Process optimization and stability of d-limonene-in-water nanoemulsions prepared by ultrasonic emulsification using response surface methodology," Ultrasonics Sonochemistry, vol. 19, no. 1, pp. 192-197, 2012.

[31] P. S. Saravana, K. Shanmugapriya, C. R. N. Gereniu et al., "Ultrasound-mediated fucoxanthin rich oil nanoemulsions stabilized by $\kappa$-carrageenan: process optimization, bioaccessibility and cytotoxicity," Ultrasonics Sonochemistry, vol. 55, pp. 105-116, 2019.

[32] D. Yusa Ali, P. Darmadji, and Y. Pranoto, "Optimasi nanoenkapsulasi asap cair tempurung kelapa dengan response surface methodology dan karakterisasi nanokapsul," Jurnal Teknologi dan Industri Pangan, vol. 25, no. 1, pp. 23-30, 2014.

[33] D. Sugiyanti, S. Anggrahini, Y. Pranoto, C. Anwar, and U. Santoso, "Low molecular weight chitosan from shrimp shell waste using steam-explosion process under catalyst of phosphotungstic acid," Oriental Journal of Chemistry, vol. 35, no. 1, pp. 193-199, 2019.

[34] Z. Ahmadi, M. Saber, A. Akbari, and G. R. Mahdavinia, "Encapsulation of Satureja hortensis L. (Lamiaceae) in chitosan/TPP nanoparticles with enhanced acaricide activity against Tetranychus urticae Koch (Acari: Tetranychidae)," Ecotoxicology and Environmental Safety, vol. 161, pp. 111119, 2018.

[35] L. Bagheri, A. Madadlou, M. Yarmand, and M. E. Mousavi, "Spray-dried alginate microparticles carrying caffeine-loaded and potentially bioactive nanoparticles," Food Research International, vol. 62, pp. 1113-1119, 2014.

[36] P. Pongsumpun, S. Iwamoto, and U. Siripatrawan, "Response surface methodology for optimization of cinnamon essential oil nanoemulsion with improved stability and antifungal activity," Ultrasonics Sonochemistry, vol. 60, article 104604, 2020.

[37] C. Tan, J. Xie, X. Zhang, J. Cai, and S. Xia, "Polysaccharidebased nanoparticles by chitosan and gum Arabic polyelectrolyte complexation as carriers for curcumin," Food Hydrocolloids, vol. 57, pp. 236-245, 2016.

[38] T. Mehmood, A. Ahmed, A. Ahmad, M. S. Ahmad, and M. A. Sandhu, "Optimization of mixed surfactants-based $\beta$-carotene nanoemulsions using response surface methodology: an ultrasonic homogenization approach," Food Chemistry, vol. 253, pp. 179-184, 2018.

[39] B. Hu, C. Pan, Y. Sun et al., "Optimization of fabrication parameters to produce chitosan-tripolyphosphate nanoparticles for delivery of tea catechins," Journal of Agricultural and Food Chemistry, vol. 56, no. 16, pp. 7451-7458, 2008.

[40] M. Hadidi, S. Pouramin, F. Adinepour, S. Haghani, and S. M. Jafari, "Chitosan nanoparticles loaded with clove essential oil: characterization, antioxidant and antibacterial activities," Carbohydrate Polymers, vol. 236, article 116075, 2020.

[41] C. C. M. Pamela Kadare, P. Maposa, and A. Dube, "Encapsulation of isoniazid in chitosan-gum Arabic and poly (lacticco-glycolic acid) PVA particles to provide a sustained release formulation," Journal of Pharmaceutics \& Pharmacology, vol. S1, 2015.
[42] I. Golfomitsou, E. Mitsou, A. Xenakis, and V. Papadimitriou, "Development of food grade $\mathrm{O} / \mathrm{W}$ nanoemulsions as carriers of vitamin $\mathrm{D}$ for the fortification of emulsion based food matrices: a structural and activity study," Journal of Molecular Liquids, vol. 268, pp. 734-742, 2018.

[43] V. Ghosh, A. Mukherjee, and N. Chandrasekaran, "Eugenolloaded antimicrobial nanoemulsion preserves fruit juice against, microbial spoilage," Colloids and Surfaces B: Biointerfaces, vol. 114, pp. 392-397, 2014.

[44] T. Mehmood, A. Ahmed, Z. Ahmed, and M. S. Ahmad, "Optimization of soya lecithin and tween 80 based novel vitamin D nanoemulsions prepared by ultrasonication using response surface methodology," Food Chemistry, vol. 289, pp. 664670, 2019.

[45] N. Mohammadpour Dounighi, M. Damavandi, H. Zolfagharian, and S. Moradi, "Preparing and characterizing chitosan nanoparticles containing hemiscorpius lepturus scorpion venom as an antigen delivery system," Archives of Razi Institute, vol. 67, no. 2, pp. 145-153, 2012.

[46] R. Iswandana, M. Zufri, and E. Anwar, "Formulasi nanopartikel verapamil hidroklorida dari kitosan dan natrium tripolifosfat dengan metode gelasi ionik," Jurnal farmasi Indonesia, vol. 6, pp. 201-210, 2013.

[47] G. C. Feyzioglu and F. Tornuk, "Development of chitosan nanoparticles loaded with summer savory (Satureja hortensis L.) essential oil for antimicrobial and antioxidant delivery applications," LWT-Food Science and Technology, vol. 70, pp. 104-110, 2016.

[48] K. T. Dewandari, S. Yuliani, and Yasni, "Ekstraksi dan karakterisasi nanopartikel ekstrak sirih merah (Piper crocatum)," Jurnal Pascapanen, vol. 10, no. 2, pp. 58-65, 2013.

[49] S. Rahaiee, S. A. Shojaosadati, M. Hashemi, S. Moini, and S. H. Razavi, "Improvement of crocin stability by biodegradeble nanoparticles of chitosan- alginate," International Journal of Biological Macromolecules, vol. 79, pp. 423-432, 2015.

[50] C. D. Kanakis, P. A. Tarantilis, H. A. Tajmir-Riahi, and M. G. Polissiou, "Crocetin, dimethylcrocetin, and safranal bind human serum albumin: stability and antioxidative properties," Journal of Agricultural and Food Chemistry, vol. 55, no. 3, pp. 970-977, 2007.

[51] M. Atefi, A. Mohammadi, and K. Nayebzadeh, "Using Bcyclodextrin and Arabic gum as wall materials for encapsulation of saffron essential oil (winter 2017)," Iranian Journal of Pharmaceutical Research, vol. 16, pp. 93-102, 2016.

[52] R. Y. Tsai, P. W. Chen, T. Y. Kuo et al., "Chitosan/pectin/gum Arabic polyelectrolyte complex: process-dependent appearance, microstructure analysis and its application," Carbohydrate Polymers, vol. 101, no. 1, pp. 752-759, 2014.

[53] M. Yulvianti, D. R. Barleany, and W. Ernayati, "Encapsulation red ginger oleoresin (Zingiber officinale var. rubrum) with chitosan-alginate as wall material using spray drying," Research Journal of Applied Sciences, Engineering and Technology, vol. 10, no. 12, pp. 1370-1378, 2015.

[54] S. M. Jafari, E. Assadpoor, Y. He, and B. Bhandari, "Encapsulation efficiency of food flavours and oils during spray drying," Drying Technology, vol. 26, no. 7, pp. 816-835, 2008.

[55] S. C. Samantha, A. S. M. Bruna, R. M. Adriana, B. Fabio, A. R. Sandro, and R. C. A. Aline, "Drying by spray drying in the food industry: micro-encapsulation, process parameters and main carriers used," African Journal of Food Science, vol. 9, no. 9, pp. $462-470,2015$. 
[56] T. C. Kha, M. H. Nguyen, P. D. Roach, and C. E. Stathopoulos, "Microencapsulation of Gac oil: optimisation of spray drying conditions using response surface methodology," Powder Technology, vol. 264, pp. 298-309, 2014.

[57] N. K. Mohammed, C. P. Tan, Y. A. Manap, A. M. Alhelli, and A. S. M. Hussin, "Process conditions of spray drying microencapsulation of Nigella sativa oil," Powder Technology, vol. 315, pp. 1-14, 2017.

[58] S. Murali, A. Kar, A. S. Patel, J. Kumar, D. Mohapatra, and S. K. Dash, "Encapsulation of rice bran oil in tapioca starchsoya protein isolate complex using spray drying," Indian Journal of Agricultural Sciences, vol. 86, no. 8, pp. 984-991, 2016.

[59] R. Harris, E. Lecumberri, I. Mateos-Aparicio, M. Mengíbar, and A. Heras, "Chitosan nanoparticles and microspheres for the encapsulation of natural antioxidants extracted from Ilex paraguariensis," Carbohydrate Polymers, vol. 84, no. 2, pp. 803-806, 2011.

[60] H. Espinosa-Andrews, O. Sandoval-Castilla, H. VázquezTorres, E. J. Vernon-Carter, and C. Lobato-Calleros, "Determination of the gum Arabic-chitosan interactions by Fourier transform infrared spectroscopy and characterization of the microstructure and rheological features of their coacervates," Carbohydrate Polymers, vol. 79, no. 3, pp. 541-546, 2010.

[61] Y. Liu, Y. Sun, Y. Li et al., "Preparation and characterization of $\alpha$-galactosidase-loaded chitosan nanoparticles for use in foods," Carbohydrate Polymers, vol. 83, no. 3, pp. 1162-1168, 2011.

[62] P. Mukhopadhyay, S. Chakraborty, S. Bhattacharya, R. Mishra, and P. P. Kundu, "pH-sensitive chitosan/alginate core-shell nanoparticles for efficient and safe oral insulin delivery," International Journal of Biological Macromolecules, vol. 72, pp. 640-648, 2015. 